\title{
A TV digital interativa terrestre e o público brasileiro: reflexões pela manutenção de uma relação de afeto*
}

\author{
Carlos Eduardo Marquioni**
}

\begin{abstract}
Resumo
Ao mesmo tempo em que os recursos de interatividade da TV digital terrestre do Brasil podem promover inclusão digital, eles também tendem a provocar variações na experiência de assistir televisão. Considerando a hipótese que o afeto desenvolvido pelo público em relação à TV pode ser justificado pelo caráter oral do brasileiro, e a partir do fato que a realização de interações mais sofisticadas requer algum letramento por alfabetização, o artigo apresenta (i) reflexões relacionadas ao risco de afastamento de parcela significativa do público brasileiro de televisão (que possui limitações de alfabetização) com a chegada da interatividade e (ii) uma sugestão inicial de abordagem que pode aproximar esse público potencialmente excluído pela necessidade de alfabetização dos recursos de interatividade da nova TV. O artigo aborda conceitualmente - por meio da noção chave de cultura - o potencial estranhamento do público com a interatividade, culminando com a apresentação que é possível utilizar recursos da própria televisão interativa para proporcionar um nível de letramento por alfabetização suficiente para realizar interações sofisticadas na TV interativa brasileira, via abordagem performancial. Palavras-chave: TV digital interativa. Letramento. Oralidade. Performance. Inclusão digital.
\end{abstract}

\footnotetext{
* Trabalho apresentado anteriormente no GP Televisão e Vídeo do XI Encontro dos Grupos de Pesquisa em Comunicação, evento componente do XXXIV Congresso Brasileiro de Ciências da Comunicação. $\mathrm{O}$ artigo apresenta reflexões preliminares desenvolvidas no projeto de doutorado em Comunicação e Linguagens em curso na Universidade Tuiuti do Paraná/UTP, orientado pela Profa. Dra. Kati Eliana Caetano.

** Professor da Faculdade de Ciências Exatas e de Tecnologia da Universidade Tuiuti do Paraná (UTP) em Curitiba-PR, Brasil. Doutorando em Comunicação e Linguagens na Universidade Tuiuti do Paraná. Tem experiência na área de Engenharia de Software (particularmente na definição de processos para desenvolvimento, qualidade e gestão de aplicativos de software).E-mail: cemarquioni@ uol.com.br
} 


\title{
The terrestrial interactive digital TV and the Brazilian audience: reflections for maintaining a relationship of affection
}

\begin{abstract}
While the interactivity of digital terrestrial TV in Brazil can promote digital inclusion it also tends to cause variations in the experience of watching television. Considering the hypothesis that the affection of the public in relation to the TV is justified by the oral nature of the Brazilian people, and getting into account that execution of more sophisticated interactions requires literacy, this article presents (i) reflections related to the risk of detachment from TV with the arrival of interactivity by a parcel of the audience of Brazilian television (which has limited literacy) and (ii) an initial proposal to minimize the risk of detachment between the new television and its audience potentially excluded due to need for literacy. The article proposes conceptual reflections - using the key notion of culture - related to the potential estrangement of the audience with the interactivity on TV, culminating with the presentation that it can be possible to use resources of the interactive television to provide enough literacy to execute sophisticated interactions on Brazilian digital interactive TV, using the performance concept.
\end{abstract}

Keywords: Interactive digital TV. Literacy. Orality. Performance. Digital inclusion.

\section{La televisión digital interactiva terrestre y el público brasileño: reflexiones para el mantenimiento de una relación de afecto}

\section{Resumen}

Mientras que la interactividad de la TV digital terrestre en el Brasil puede promover la inclusión digital, también tiende a causar variaciones en la experiencia de ver televisión. Teniendo en cuenta la hipótesis que el afecto del público por la televisión puede ser justificado por el carácter oral del brasileño, y del hecho de que la aplicación de las interacciones más sofisticadas exige cierto nivel de alfabetización, este artículo presenta (i) reflexiones relacionadas con el riesgo de distanciamiento entre una parte de la audiencia brasileña (que tiene la alfabetización limitada) y los medios de comunicación, con la llegada de la interactividad y (ii) una propuesta inicial para promover la unidad entre la audiencia que es potencialmente excluida debido a la necesidad de alfabetización con la nueva televisión. El artículo propone reflexiones conceptuales - utilizando la noción clave de la cultura - en relación con la enajenación potencial de la audiencia con la interactividad en la televisión, y la presentación que es posible utilizar recursos de interactividad en la televisión para proporcionar un nivel de alfabetismo suficiente para llevar a cabo interacciones complejas en TV digital interactiva brasileña a través del concepto de performance.

Palabras clave: Televisón digital interactiva. Alfabetismo. Oralidad. Performance. Inclusión digital. 


\section{Introdução}

possibilidade de o telespectador brasileiro efetuar ações
de interatividade utilizando a TV digital terrestre oferece
reflexões relacionadas à variação na experiência de assistir televisão que deve ocorrer com este recurso tecnológico. A variação tende a ser mais evidente nos casos em que as interações forem realizadas no formato "interatividade plena" (FERRAZ, 2009 , p.34), quando o aparelho televisor adquire características semelhantes às de um computador pessoal conectado à Internet.

Um exemplo do uso da TV em interatividade plena envolve a realização de operações de t-commerce (GAWLINSKI, 2003, p.88137), nome atribuído às compras realizadas via televisão. Neste formato de consumo, ao assistir um anúncio publicitário, ou mesmo durante a veiculação do conteúdo da grade de programação, existe a possibilidade técnica de o espectador utilizar o próprio televisor para adquirir um produto ou serviço de seu interesse. Enquanto ocorre a operação, o monitor de TV é utilizado como se fosse um microcomputador em ambiente Web (inclusive com interfaces/páginas para entrada de dados) e o controle remoto um dispositivo equivalente ao teclado, através do qual é possível ao espectador/usuário/consumidor informar os dados requeridos para efetuar a compra (dados pessoais, dados de pagamento, endereço para entrega etc.).

O exemplo ilustra uma diferença fundamental entre os modos de ver a TV digital interativa e a televisão terrestre convencional, relacionada à capacidade de leitura e escrita necessária para executar formas de interação mais sofisticadas: da mesma forma que nas operações de compra pela Web, o espectador necessita ainda ler e entender os termos e condições da transação comercial informados pelo fornecedor do produto ou serviço desejado. Esta espécie de pré-requisito de letramento por alfabetização do espectador pode limitar a utilização dos recursos mais avançados por uma parcela significativa do público da TV digital terrestre. A afirmação é justificada pelo fato que uma parcela significativa da população do país possui limitações relacionadas ao letramento por alfabetização:

Intercom - RBCC

São Paulo, v.35, n.2, p. 4II-429, jul./dez. 2012

413 
os dados divulgados pelo relatório PNAD (IBGE, 2010, s/p) no segundo semestre de 2010 apresentam um índice de analfabetismo estimado em 9,7\% da população, e um índice de analfabetismo funcional $^{1}$ de 20,3\% no país. Ainda que o relatório aponte tendência de queda do indicador na comparação com os índices observados nos anos anteriores, aproximadamente $1 / 3$ da população brasileira tem problemas para ler e escrever: este grupo deve ter dificuldades para utilizar os recursos de interatividade plena.

Ao se constatar que os meios eletrônicos possibilitam "a presença da oralidade como um fato contemporâneo entre nós" (HAVELOCK, 1996, p.138), que o Brasil constitui uma "sociedade oralizada por excelência” (BARBOSA, 2010a, p.21), e analisar estes fatos em conjunto com os índices de analfabetismo e analfabetismo funcional divulgados, é possível concluir que a oralidade da televisão deve ter contribuído para aproximar o público da TV. $\mathrm{O}$ acesso à televisão, que requer apenas alguma educação do olhar (BARBOSA, 2010b) para que se tenha em relação ao dispositivo uma "sensação de acesso direto, sem mediação" (WILLIAMS, 2005 , p.135) parece ter proporcionado ao espectador brasileiro a sensação da "mensagem de tevê como algo de 'natural' no interior de sua casa. [...] [A televisão] finge ser o olho da família assestado para a espontaneidade dos acontecimentos do mundo" (SODRÉ, 2010, p.59). A espécie de casamento entre a característica oral do público brasileiro e do meio possibilitou que o espectador se reconhecesse na televisão. O termo casamento parece apropriado não apenas pelo fato de o aparato fazer parte do convívio doméstico cotidiano, mas por ser possível observar "o estabelecimento de

\footnotetext{
${ }^{1}$ Uma pessoa considerada funcionalmente analfabeta apresenta dificuldades para ler e compreender uma frase completa. "Segundo definição da United Nations Organization for Education, Science and Culture - UNESCO, funcionalmente alfabetizada é a pessoa que pode participar de todas as atividades em que a alfabetização é necessária para o funcionamento efetivo do seu grupo e comunidade e também para lhe permitir continuar a utilizar a leitura, a escrita e o cálculo para seu próprio desenvolvimento e da comunidade" (IBGE, 2010, s/p). O índice estimado de analfabetismo funcional é calculado "pela proporção de pessoas de 15 anos ou mais de idade com menos de 4 anos de estudo completos em relação ao total de pessoas de 15 anos ou mais de idade" (IBGE, 2010, s/p).
} 
relação afetiva com o telespectador" (SODRÉ, 2010, p.63) - especialmente por parte daqueles espectadores com limitações de alfabetização, que são "maltratados pelas forças escritas [...] [e têm como opção] comprar um transistor ao invés de fazer uma assinatura de jornal" (ZUMTHOR, 2010, p.28). É no sentido desta relação afetiva, de proximidade íntima estabelecida entre a TV e seu público que se considera o uso do termo afeto neste artigo.

O cenário, que auxilia na compreensão do sucesso da TV no país aponta também para o risco potencial associado à mudança na maneira de assistir televisão que desponta com a chegada da interatividade plena. Este trabalho apresenta reflexões iniciais que constituem sugestões para abordar o tema da interatividade considerando o afeto desenvolvido pelo público em relação à televisão. Para a apresentação das reflexões, o trabalho é organizado em duas seções, além desta Introdução e das Considerações Finais. Em Cultura, oralidades e letramentos a noção de cultura é apresentada como fundamental para abordar contextos envolvendo mudanças de hábitos na sociedade em função da disponibilidade de novos recursos tecnológicos. A seção Performance e tecnologia interativa: uma nova oralidade? apresenta a noção de performance associada à forma de escrita praticada na Internet e a dois recursos tecnológicos disponíveis na TV digital brasileira como constituintes de um contexto que pode possibilitar acesso à interatividade plena inclusive pela parcela do público que tem letramento por alfabetização limitado. Finalmente, as Considerações Finais sintetizam as análises realizadas e apresentam desdobramentos para o trabalho.

Assim, as reflexões preliminares apresentadas ao logo das seções deste trabalho procuram alternativas para equacionar um questionamento chave que pode impactar diretamente a estratégia de inclusão digital via TV digital interativa: considerando que o caráter oral e as restrições de alfabetização do brasileiro podem eventualmente promover um afastamento da audiência em relação à televisão a partir do momento em que for requerida capacidade de escrita para interações sofisticadas diretamente via TV, como abordar o letramento por alfabetização no contexto da nova TV de modo a minimizar os riscos de estranhamento da audiência com o dispositivo, e seu eventual afastamento? A pesquisa em 
curso considera que a resposta à pergunta passa necessariamente pela noção de cultura, associada à necessidade de preparação do público para interagir em formatos mais complexos (letramento eletrônico) e à aquisição de certa competência para leitura e escrita durante as ações de interatividade (letramento por alfabetização) - o presente artigo aborda conceitualmente este último item, indicando que recursos tecnológicos da TV digital podem viabilizar este letramento.

\section{Cultura, oralidades e letramentos}

A noção de cultura é abordada neste trabalho como "o produto de todo um povo, significados comuns oferecidos [...] [, que] se constituem na vida, são feitos e refeitos, e não podem ser prescritos" (WILLIAMS, 1989, p.8). Segundo essa definição, a cultura é constituída na duração: ela está permanentemente em processo e os significados são estabelecidos pelos atores sociais à medida que esses atores estabelecem contato e utilizam os produtos culturais - inclusive com aparatos tecnológicos. Em relação à televisão no Brasil, os significados culturais definidos englobam inclusive o reconhecimento do público na TV, estabelecendo um contexto complexo (MORIN, 1990, p.20) no qual a televisão deve ser abordada enquanto "sistema, [cujas] [...] peças não se compõem apenas de metal, válvulas ou transistores - as pessoas fazem parte delas" (SODRÉ, 2010, p.13). A noção possibilita afirmar que é demasiado simplificadora uma análise que trate da disponibilização dos recursos tecnológicos per se. No caso da TV digital interativa, os significados definidos ao longo de mais de meio século de convívio do público com a televisão convencional no Brasil passam a ser redefinidos com os novos requisitos necessários para utilização da tecnologia interativa. Um dos requisitos com influência cultural determinante para compreensão e uso dos recursos da TV digital é o letramento por alfabetização do público, em função da capacidade de leitura e escrita requerida para realizar ações de interatividade plena.

Mas é necessário observar que a noção de cultura apresentada indica que toda nova tecnologia potencialmente influencia 
os significados definidos pela sociedade na qual é disponibilizada, a partir do momento em que os atores sociais passam a conviver com ela. Assim, se a disponibilização da interatividade plena pode provocar variações no convívio de uma parcela da sociedade com o meio televisual, outras tecnologias provocaram variações no passado - inclusive a própria TV, que necessitou que o público fosse preparado antes de sua chegada efetiva (BARBOSA, 2010b, p.15-35). Uma vez que o letramento tem papel determinante no contexto da TV digital interativa, e a escrita pode ser considerada ela própria uma tecnologia (ONG, 1988, p.97), é razoável avaliar os impactos provocados pela escrita alfabética na Grécia antiga para procurar índices que auxiliem a analisar os impactos do recurso de interatividade plena na TV digital brasileira.

A escrita possibilitou que a sociedade da Grécia passasse, aproximadamente no século 5 a.C., de um "estado oral da mente" (HAVELOCK, 1963, p.41) para "um novo estado mental - a mente alfabética” (HAVELOCK, 1994, p.15). A mente em estado estritamente oral é associada ao conceito de oralidade primária, praticada pelas "pessoas que desconhecem inteiramente a escrita" (ONG, 1988, p.14). Uma vez que a noção de oralidade primária é relacionada a "uma cultura totalmente desprovida de qualquer conhecimento da escrita" (ONG, 1988, p.19), a partir da divulgação da escrita este formato de oralidade - em sentido estrito praticamente desapareceu: "se pode não dominar o código escrito, mas saber sua função na sociedade e fazer uso dele" (BARBOSA, 2010a, p.89). Ainda que o indivíduo não saiba ler e escrever, ele se encontra imerso em um ambiente sócio-cultural-comunicacional que não é mais de oralidade primária na essência: de alguma forma, este indivíduo se relaciona com formas de escrita (letramento).

Merece destaque e interessa especialmente para este trabalho o fato que a passagem do estado oral da mente para a mente alfabética não ocorreu rapidamente. Apesar de apresentado anteriormente que essa passagem ocorreu no século 5 a.C., é necessário compreender que "a revolução [provocada pela escrita] era algo que se estendia por muitas gerações, de modo demasiado gradual para que os participantes tivessem consciência de sua base técnica, e do que estavam fazendo com ela" (HAVELOCK, 1994, p.36). 
Como fenômeno cultural, o letramento por alfabetização necessitou que os significados fossem redefinidos pelos atores sociais na duração. No caso da TV digital interativa, um programa de alfabetização em massa parece pouco apropriado para tratar do tema do letramento no Brasil, inclusive porque o acesso à escrita em padrão formal culto não é imediato e, mesmo após anos de aprendizado, "[r]aras pessoas se atrevem a dizer que conhecem a língua” (PERINI, 1997, p.11).

Para entender a complexidade relacionada à "equação oralidade-letramento" (HAVELOCK, 1996, p.46) é fundamental observar que (i) apesar da invenção do alfabeto ter caráter "democratizante no sentido de que era fácil para qualquer um aprender" (ONG, 1988, p.106), o acesso a esta tecnologia "dependeria não apenas do invento em apreço, mas também da organização e manutenção de ensino escolar de leitura num nível elementar" (HAVELOCK, 1994, p.82). No caso da TV digital, disponibilizar o recurso da interatividade não garante sua utilização. Além disso, (ii) a passagem do estado oral para o estado alfabético da mente não significou uma redução da oralidade e, a rigor, a oralidade na Grécia não acabou a partir do letramento: "a Antiguidade mais tardia nunca descartou por completo o hábito da oralidade" (HAVELOCK, 1994, p.37), ao ponto de ser possível a metáfora que no período, enquanto a "musa da oralidade [...] está a aprender a ler e a escrever - mas, em simultâneo, continua a cantar" (HAVELOCK, 1996, p.34). Finalmente, os termos estado oral e mente alfabetizada não devem ser compreendidos caracterizando juízo de valor ou definindo a oralidade como uma forma de Comunicação inferior em relação à escrita. A afirmação é justificada não apenas a partir da constatação de que parte significativa da cultura grega se desenvolveu em um ambiente essencialmente oral ${ }^{2}$, mas também pela evidência que a escrita foi desenvolvida a partir da fala. Neste sentido, quando se argumenta neste trabalho a necessidade de encontrar alternativas

\footnotetext{
${ }^{2}$ Como exemplo pode ser citado o período entre "1100 e 700 a.C., [quando] os gregos eram totalmente não-letrados [...] [e estabeleceram] as primeiras formas da organização social e da produção artística que vieram a ser sua glória" (HAVELOCK, 1994, p. 48). Assim, embora seja possível considerar que houve um desenvolvimento significativo das ciências a partir da cultura escrita, não é razoável considerar que a forma escrita seja melhor que a oral.
} 
para acesso da população com limitações de letramento por alfabetização à interatividade na TV digital não estão sendo procuradas formas para migração do caráter oral da população brasileira para um novo padrão letrado, mas alternativas de acesso à interatividade plena (que requer algum letramento por alfabetização para ser realizada) também por essas pessoas.

A tecnologia da escrita viabilizou a aceleração do avanço científico, pois o "alfabeto tornou possível a formulação do enunciado novo e inesperado, que antes não era familiar e era até 'impensado"” (HAVELOCK, 1994, p.85). O avanço científico, por sua vez, proporcionou o desenvolvimento de um contexto tecnológico que conduziu a sociedade para a oralidade secundária, relacionada à "cultura de alta tecnologia, na qual uma oralidade é alimentada pelo telefone, pelo rádio, pela televisão ou por outros dispositivos eletrônicos, cuja existência e funcionamento dependem da escrita e da impressão" (ONG, 1988, p.19).

De acordo com esta definição, os meios eletrônicos de Comunicação (como o rádio ou a televisão) inserem a sociedade em uma oralidade de segunda ordem ${ }^{3}$. Paradoxalmente, a sensação de acesso não mediado proporcionado pela oralidade da TV é possibilitada pelo letramento. De fato, é possível afirmar que o letramento está inserido na televisão (apesar da aparência de oralidade) não apenas porque o aparato tecnológico teve seu desenvolvimento relacionado ao letramento, mas também porque

\footnotetext{
${ }^{3}$ É importante a ressalva que a definição de oralidade secundária proposta por Walter Ong difere daquela apresentada por Paul Zumthor: apesar de os dois autores fazerem parte do referencial teórico deste trabalho, em relação à noção de oralidade secundária optou-se por utilizar a noção proposta por Ong. As duas definições diferem essencialmente. Enquanto para Ong existe uma forma de oralidade nomeada secundária, que passa a ser observada a partir do letramento e dos meios eletrônicos de Comunicação, Zumthor utiliza a noção de "uma oralidade coexistente com a escrita e que, segundo esta coexistência, pode funcionar de dois modos: seja como oralidade mista [...]; seja como oralidade segunda" (ZUMTHOR, 2010, p.36) para referenciar a forma de oralidade de uma sociedade que tem consciência da existência da escrita, e apresenta ainda outra forma de oralidade, que nomeia de "oralidade mecanicamente mediatizada, logo diferenciada no tempo e/ou no espaço" (ZUMTHOR, 2010, p.36). Optou-se pela definição de Ong devido ao fato que, além de ela ser mais facilmente compreensível, também engloba a noção proposta por Zumthor.
} 
"a linguagem de quase toda a programação é, na sua origem, uma linguagem escrita" (PRETI, 1991, p.233). Em outros termos, ainda que a televisão veicule seu conteúdo de modo oral, "se atentarmos para algumas características diferenciadoras do oral e do escrito, iremos ver que, na verdade, a TV produz por escrito e constrói rigorosamente por escrito esses textos para que eles pareçam orais" (ROCCO, 1991, p.253).

Uma evidência contemporânea de que a escrita continua em processo (por se tratar de tecnologia e sofrer influência cultural) envolve a forma praticada na Comunicação mediada por computador - especialmente no ambiente da Internet -, que possui "flagrante informalidade da linguagem" (HILGERT, 2000, p.50). A escrita praticada na Internet pode ser entendida como "um texto conceptualmente falado, mas compulsoriamente realizado por escrito" (HILGERT, 2000, p.52). O trabalho considera que o uso desta forma de escrita pode ser uma alternativa para viabilizar as ações de interatividade plena no caso da TV digital no Brasil, por aproximar as interações da "língua da comunidade" (PRETI, 1981, p.232): a oralização da escrita observada no ambiente da Internet, se migrada para o ambiente da TV digital deve aumentar a probabilidade de interatividade plena.

Uma vez que é possível constatar gradações de uso da fala e da escrita - "existe uma escrita informal que se aproxima da fala e uma fala formal que se aproxima da escrita, dependendo do tipo de situação comunicativa" (KOCH, 2007, p.78) -, essa forma de escrita não caracteriza uma maneira incorreta de escrever (exceto se lhe for aplicada uma correção relacionada ao padrão culto). Inclusive porque a noção de "conhecimento implícito" (PERINI, 1997, p.12) como o conhecimento suficiente ao indivíduo para que ele execute um conjunto de funções desejadas possibilita tanto afirmar que o padrão culto não é praticado pela maioria da população quanto constatar a existência de mais de uma língua no Brasil:

o português (que aparece no texto escrito) não é nossa língua materna. A língua que aprendemos com nossos pais, irmãos e avós é a mesma que falamos, mas não é a que escrevemos. As diferenças são bastante profundas, a ponto de, em certos casos, impedir a Comunicação [...]. [H]á duas línguas no Brasil: uma que se escreve (e que recebe o nome de 'português'); e outra que se fala (PERINI, 1997, p.35-36). 
A forma de escrita praticada na Internet pode ser conceitualmente analisada como uma "'re-oralização', [...] uma tentativa de retorno ao oral" (HILGERT, 2000, p.42) pois é sabido que o texto falado "emerge no próprio momento da interação: ele é seu próprio rascunho" (KOCH, 2007, p.78). Nesta perspectiva de análise "não há crise lingüística, mas há transformações, pois as alterações no uso lingüístico são a natural decorrência das alterações sociais" (PRETI, 1991, p.239). Evidentemente não se propõe aqui o abandono do padrão culto da língua, nem tampouco se pretende aprofundamento em aspectos gramaticais ou de linguística neste artigo. Espera-se apenas destacar a relevância de considerar o caráter cultural para abordar de forma reflexiva formas de escrita alternativas para viabilizar as ações de interatividade plena considerando a complexidade envolvida.

A próxima seção apresenta como esta forma de escrita mais livre da estrutura gramatical pode, associada à noção de performance e a alguns recursos tecnológicos disponíveis na TV digital interativa, caracterizar uma alternativa para auxiliar na preparação do público para realizar ações de interatividade plena.

\section{Performance e tecnologia interativa: uma nova oralidade?}

Esta seção apresenta uma proposta inicial para abordar as limitações relacionadas ao letramento que podem restringir a realização de ações de interatividade plena. Merece destaque, contudo, o fato que se trata de uma sugestão que não deve ser considerada conclusiva: a complexidade envolvida inviabiliza esgotar o assunto neste trabalho.

A proposta envolve utilizar a noção de performance (ZU. MTHOR, 2007) em conjunto com a forma de escrita praticada na Internet e os recursos tecnológicos da audiodescrição ${ }^{4}$ e

\footnotetext{
${ }^{4}$ A audiodescrição corresponde a uma "locução em língua portuguesa, sobreposta ao som original do programa, destinada a descrever imagens, sons, textos e demais informações que não podem ser percebidos ou compreendidos por pessoas com deficiência visual. A informação deve ser enviada pelo provedor de conteúdo [...] que, a critério do usuário, pode ser selecionado" (ABNT NBR 15604, 2007, p.40).
} 
audiolocução ${ }^{5}$ disponíveis na TV digital brasileira para auxiliar a preparar o público para interagir em formato pleno. A abordagem deriva da hipótese de que o espectador poderia desenvolver sua capacidade de ler e escrever utilizando a TV, caso fosse proporcionado um ambiente que viabilizasse este desenvolvimento. As reflexões a seguir procuram evidenciar que a proposta não corresponde a um programa de alfabetização formal.

Performance corresponde à recuperação de sensações associadas à experiência pessoal ou social de um indivíduo a partir de estímulos que são, via de regra, orais. $\mathrm{O}$ uso do termo recuperação pressupõe (i) que o contexto relacionado à sensação de performance deve ser conhecido (tenha ocorrido anteriormente) e que (ii) há uma noção de repetição intrínseca à performance, mas que não deve caracterizar redundância (ZUMTHOR, 2007) pois a performance deve ser associada a sensações agradáveis. Assim, diz-se que, se um indivíduo ao ouvir uma canção (presencialmente ou via um aparato tecnológico) se recorda de situação semelhante e volta a ter sensações experimentadas anteriormente ao ouvir a mesma canção (ou uma canção parecida), teve uma experiência de performance.

Vale observar ainda que o caráter de repetição sem redundância é proporcionado no caso da TV devido ao fluxo planejado televisual (WILLIAMS, 2005, p.86). Os programas da grade de programação "atuam invariavelmente como demarcadores do tempo de vida dos indivíduos, sincronizando suas atividades dentro de um todo maior" (BAITELLO JR, 2009, p.102). Entende-se que a ritualização (BAITELLO JR, 2009, p.104) que o fluxo planejado auxilia na atribuição de contexto à vida do público de TV via performance.

Embora os estímulos relacionados à performance sejam tipicamente orais, é possível que a experiência ocorra também durante a leitura individual e silenciosa de um texto literário (ZUMTHOR, 2007, p.33), não apenas devido ao fato de que a escrita foi elaborada a partir da fala, mas porque é possível falar em graus de

\footnotetext{
${ }^{5}$ A audiolocução permite "a inserção de locução, em português, destinada a possibilitar que pessoas com deficiência visual e pessoas com deficiência intelectual selecionem as opções desejadas em menus e demais recursos interativos. [...] deve ser enviado pelo provedor de conteúdo" (ABNT NBR 15604, 2007, p.40).
} 
performance. A performance relacionada à "leitura solitária e puramente visual marca o grau performancial mais fraco, aparentemente próximo do zero" (ZUMTHOR, 2007, p.69), constatado nas situações em que o corpo reage ao texto lido. Em grau oposto àquele observado na experiência de performance relacionada à leitura individual e silenciosa se enquadra a "performance com audição acompanhada de uma visão global da situação de enunciação [...] [, que constitui uma] performance completa [ou que poderia ser classificada como sendo de grau máximo]" (ZUMTHOR, 2007, p.69). É possível afirmar então que a experiência de performance ocorre no "momento da recepção [do texto - oral ou escrito]: momento privilegiado, em que o enunciado é realmente recebido" (ZUMTHOR, 2007, p.50).

A performance completa, que associa audição e visão, possibilita compreender a TV convencional como um ambiente de performance por excelência. A constatação autoriza apresentar outra hipótese para o desenvolvimento do afeto do público brasileiro em relação à TV convencional: complementar à sensação de quase ausência de mediação e acesso ao meio independente da capacidade de leitura e escrita, a característica de performance do dispositivo provoca sensações agradáveis que aproximam o público do meio.

As reflexões iniciais realizadas possibilitam formular a hipótese provisória de que o cenário que se configura em relação à TV digital interativa terrestre pode ser entendido como a necessidade de coexistência entre as performances completa (basicamente oral) e aquela próxima do zero (relacionada ao letramento). Para que esta coexistência seja transparente ao público é possível considerar a utilização de recursos tecnológicos disponibilizados pela TV digital brasileira, que podem tornar a leitura não solitária e puramente visual: tratam-se da audiodescrição e da audiolocução. Estes recursos podem ser utilizados para ler (e falar) o conteúdo apresentado na televisão para o público (inclusive o conteúdo da interface para interatividade plena). De forma análoga ao que ocorria com os jornais no Brasil ainda no início do século 19, quando era possível observar "claros índices de oralidade" (BARBOSA, 2010a, p.45) e ocorria a leitura do texto impresso em voz alta e em público para que os indivíduos não letrados tivessem acesso ao conteúdo, no 
século 21 uma adaptação equivalente pode ocorrer em relação à TV digital. É possível conceber ainda o uso de um recurso que fale o conteúdo à medida que o espectador escreve (insere dados) na TV digital interativa durante o ato interativo.

Ao associar o caráter performático da televisão a recursos que lêem (e falam) com o espectador à medida que informações são apresentadas ou inseridas no televisor, a televisão ultrapassa o aspecto democratizante relacionado ao aspecto oral. Relacionando as formas das letras escritas na tela do televisor aos sons correspondentes emitidos é possível que o público aprenda a partir da rememoração de situações experimentadas anteriormente (performance associada ao ato de escrever).

Uma vez que não se trata de um programa de alfabetização formal, entende-se que este aprendizado deve ocorrer sem a preocupação com o rigor do padrão culto da língua. Se o objetivo (ao menos em um momento inicial) é possibilitar a Comunicação considerando os aspectos de oralidade do público brasileiro para manter a relação de afeto desenvolvido com o meio, e existe na Web a aproximação entre a forma escrita e a falada, o deslocamento desta tendência para o ambiente da TV digital pode potencializar o uso dos recursos interativos, eventualmente caracterizando uma alternativa eficiente para a inclusão digital utilizando a televisão digital. Esta inclusão seria facilitada pelo fato de a TV convencional estar "presente em cerca de 92,6\% dos lares brasileiros" (PATRIOTA, 2009, p.108), e um conversor ser suficiente para que estes televisores tenham acesso às ações de interatividade ${ }^{6}$. Em outros termos: entende-se que a inclusão digital não é limitada ou viabilizada pela tecnologia per se, mas pela garantia de formas de acesso e uso da tecnologia (da mesma forma que em relação a outros artefatos culturais).

É possível estabelecer neste ponto nova relação entre o período da invenção da escrita na Grécia e o contexto da TV digital

\footnotetext{
6 "o projeto de implantação da TV digital no Brasil prevê o aproveitamento do parque de televisores analógicos coloridos instalados e a oferta de caixas de conversão acessível às classes $\mathrm{C}, \mathrm{D}$ e $\mathrm{E}$ que viabilizem o uso de aplicativos digitais residentes mínimos [...] para possibilitar níveis de interação com os diferentes públicos” (BARBOSA FILHO; CASTRO, 2008, p.50).
} 
interativa brasileira, abordando os dois casos como situações de performance. Na primeira situação as musas foram utilizadas para transmitir o conhecimento e a tradição entre as gerações através de poemas orais; assim, é possível afirmar que as musas não eram "filhas da inspiração ou da invenção, mas basicamente da memorização" (HAVELOCK, 1963, p.100). Esses poemas, repetidos acusticamente, possibilitavam o registro e uso posterior inclusive de instruções funcionais: a arte era aplicada segundo sua definição de artifício e "a poesia era produto de uma arte imaginada para entreter [...] [mas que] tem também de ser vista como funcional, um método para preservar [...] hábitos sociais [...] [,] leis [...] e convenções" (HAVELOCK, 1996, p.76). Em relação à TV digital, a abordagem de performance aplicada à interatividade pode caracterizar o aparecimento de uma musa que utilizaria sua arte (artifício) orientada ao aspecto funcional de auxiliar o público a realizar ações de interatividade.

Assim, a TV digital interativa poderia ser entendida como uma forma de "partilha do sensível" (RANCIÈRE, 2005, p.26) relacionada ao letramento, devido (i) à possibilidade de reflexão proporcionada aos espectadores que passariam a ter acesso ao código escrito e (ii) às novas experiências - inclusive de performance - que esse público, até então à margem do letramento, teria com a compreensão e uso desse código. Este caráter sensível e a democratização de acesso observada com a abordagem parecem justificar a formulação de uma nova forma de oralidade (uma terceira oralidade ${ }^{7}$ ): é constituído um cenário que, embora utilize elementos que poderiam ser classificados simplesmente como de convergência entre a TV e o microcomputador, talvez caracterize de fato uma nova forma comunicacional.

A terceira oralidade parece diferir da segunda (da qual deriva) no sentido que ela não é relacionada simplesmente a um dispositivo tecnológico de mediação (não é apenas uma oralidade mediada). Mais que isso, esta terceira oralidade seria vinculada

\footnotetext{
${ }^{7}$ Merece destaque o fato que o termo terceira oralidade referência a noção de segunda oralidade de Walter Ong, mas não as noções de oralidade mista, oralidade segunda ou oralidade mecanicamente mediatizada de Paul Zumthor, conforme comentário apresentado em nota de rodapé anterior.
}

Intercom - RBCC 
a uma classe de dispositivos tecnológicos - à qual pertence a TV digital interativa - que não falam para o telespectador, mas com o telespectador. Enquanto no caso da oralidade secundária eram caracterizadas "vozes mediatizadas" (ZUMTHOR, 2010, p.27) que falavam, mas não recebiam resposta do público (ao menos não diretamente ou através do próprio dispositivo), na terceira oralidade seriam viabilizados diálogo e interação efetivos.

\section{Considerações finais}

Tanto em termos da definição da tecnologia quanto da preparação do conteúdo para exibição, a televisão convencional utilizou recursos da escrita que acabaram por proporcionar ao público a sensação de espontaneidade e oralidade que possibilitou a aproximação do espectador brasileiro. A TV digital, por outro lado, requer deste mesmo espectador algum conhecimento do código escrito para a realização de ações de interatividade mais sofisticadas. A mudança de cenário é crítica em um país com limitações de alfabetização. Assim, não basta disponibilizar o aparato tecnológico para que ele seja utilizado: é necessário avaliar o impacto cultural associado e realizar reflexões para definir alternativas que facilitem o acesso a esta nova forma de televisão. $\mathrm{O}$ trabalho apresentou o uso da noção de performance, associada à forma de escrita próxima do discurso oral que vem sendo praticada na Internet e aos recursos tecnológicos da audiodescrição e audiolocução como uma alternativa para inserir no contexto da interatividade plena os espectadores potencialmente excluídos devido à necessidade de letramento (aproximadamente $1 / 3$ da população brasileira).

Alguns desdobramentos evidentes para este trabalho envolvem (i) avaliar se a abordagem proposta efetivamente é eficiente, ou ainda se esta eficiência seria observada apenas nos casos de analfabetismo funcional (se o caráter de performance associado aos recursos tecnológicos disponíveis pode surtir efeito inclusive nos casos de analfabetismo total). É possível ainda avaliar (ii) como o aprendizado do padrão culto da língua pode ser disponibilizado no cenário apresentado, se este aprendizado do padrão culto é efetivamente necessário (em outros termos: se a aquisição de uma 
espécie de letramento para interação seria suficiente) e o que significaria a utilização da forma de escrita mais próxima da oralidade no momento de realizar ações de interatividade plena em situações que envolvem aspectos legais/contratuais (como uma operação de compra). Em relação a este último item, talvez mais significativo que simplesmente apontar as restrições de formalidade associadas à realização de uma operação de t-commerce utilizando uma forma de escrita que não segue o padrão culto seja analisar conceitualmente se tratar apenas de uma nova forma de interação, ou se eventualmente está se configurando a emergência de uma nova linguagem (ou de uma nova forma comunicacional) a partir desta nova TV.

É fato que o público brasileiro estabeleceu ao longo de mais de meio século uma relação de identificação e afeto em relação à televisão, que indubitavelmente contribuiu para o sucesso do meio. Neste sentido, é fundamental aprofundar as reflexões iniciais propostas neste trabalho, procurando alternativas que mantenham esta relação - inclusive por respeito ao espectador.

\section{Referências}

ABNT NBR 15604. Norma Brasileira: Televisão digital terrestre - Receptores. Rio de Janeiro: ABNT, 2007. Disponível: http://www.dtv.org.br/download/ pt-br/ABNTNBR15604_2007Vc_2008.pdf. Acesso: 16/04/2010.

BAITELLO JR, Norval. Mídia, tempo, ordem, sincronização. In: $\mathrm{O}$ animal que parou os relógios: Ensaios sobre Comunicação, cultura e mídia. São Paulo: Annablume, [1997] 2009. p. 94-104.

BARBOSA FILHO, André; CASTRO, Cosette. Comunicação digital: Educação, tecnologia e novos comportamentos. São Paulo: Paulinas, 2008.

BARBOSA, Marialva Carlos. História cultural da imprensa: Brasil 1800. 1900. Rio de Janeiro: Mauad Editora, 2010a.

. Imaginação televisual e os primórdios da TV no Brasil. In: RIBEIRO, Ana Paula Goulart; SACRAMENTO, Igor; ROXO, Marco. História da televisão no Brasil: Do início aos dias de hoje. São Paulo: Editora Contexto, 2010b. p. 15-35.

FERRAZ, Carlos. Análise e perspectivas da interatividade na TV Digital. In: SQUIRRA, Sebastião; FECHINE, Yvana (org.). Televisão digital: desafios

Intercom - RBCC

São Paulo, v.35, n.2, p. 4II-429, jul./dez. 2012 


\section{CARLOS EDUARDO MARQUIONI}

para a Comunicação - Livro da COMPÓS 2009. Porto Alegre: Editora Sulina, 2009. p. 15-43.

GAWLINSKI, Mark. Interactive television production. Oxford: Focal Press, 2003.

HAVELOCK, Erick A. A musa aprende a escrever: reflexões sobre a oralidade e a literacia da Antiguidade ao presente. Lisboa: Trajectos 33, [1988] 1996.

- A revolução da escrita na Grécia e suas conseqüências culturais. São Paulo: Editora UNESP/Paz e Terra, [1982] 1994.

. Preface to Plato. London: Belknap Press, 1963.

HILGERT, José Gaston. A construção do texto 'falado' por escrito: A conversação na Internet. In: PRETI, Dino. Fala e escrita em questão. São Paulo: Humanitas FFLCH/USP, 2000. p. 17-55.

IBGE. PNAD: Pesquisa Nacional por Amostra de Domicílios: Síntese de indicadores 2009. Disponível em: < http:/www.ibge.gov.br/home/estatistica/ populacao/trabalhoerendimento/pnad2009/pnad_sintese_2009.pdf $>$. Acesso em: 11 dez. 2010.

$\mathrm{KOCH}$, Ingedore Villaça. A inter-ação pela linguagem. São Paulo: Editora Contexto, [1993] 2007.

MORIN, Edgar. Introdução ao pensamento complexo. Lisboa: Instituto Piaget, 1990.

ONG, Walter. Oralidade e cultura escrita. Campinas: Papirus, [1982] 1998.

PATRIOTA, Karla Regina M. P. Sob demanda, convergente e interativa. A customização da Publicidade na Televisão Digital. In: SQUIRRA, Sebastião; FECHINE, Yvana (org.). Televisão digital: desafios para a Comunicação Livro da COMPÓS 2009. Porto Alegre: Editora Sulina, 2009. p. 108-127.

PERINI, Mário A. Sofrendo a gramática: Ensaios sobre a linguagem. São Paulo: Editora Ática, 1997.

PRETI, Dino. A linguagem da TV: O impasse entre o falado e o escrito. In: NOVAES, Adauto (org.). Rede imaginária: televisão e democracia. São Paulo: Companhia das Letras, 1991. p. 232-239.

RANCIÈRE, Jacques. A partilha do sensível. São Paulo: Editora 34, 2005. 
ROCCO, Maria Thereza Fraga. As palavras na TV: Um exercício autoritário? In: NOVAES, Adauto (org.). Rede imaginária: televisão e democracia. São Paulo: Companhia das Letras, 1991. p. 240-256.

SODRÉ, Muniz. O monopólio da fala: função e linguagem da televisão no Brasil. Petrópolis: Editora Vozes, [1977] 2010.

WILLIAMS, Raymond. Television: Technology and cultural form. Padstow: Routledge Classics, [1974] 2005.

. Culture is ordinary [1958]. In: Resources of hope: culture, democracy, socialism. p. 3-18. Londres: Verso, 1989.

ZUMTHOR, Paul. Introdução à poesia oral. Belo Horizonte: Editora UFMG, [1983] 2010.

Performance, recepção, leitura. São Paulo: Cosac Naify, [1978] 2007.

Recebido em: 30.11 .2011

Aceito: 30.07 .2012 


\section{Comunicação, educação e cultura na era digital}

Reúne textos apresentados no XXXII Congresso nacional da Intercom de 2009 sobre Comunicação, Educação e Cultura. Porém o faz atentando para os tempos atuais em que vivemos. As variadas vozes de eminentes pesquisadores foram chamadas para compor esta récita polifônica. A almejada pluralidade de pontos de vista que exorcizam de vez a tão perniciosa homogeneidade do execrável pensamento único está aqui plena a contribuir para a difusão dos mais recentes textos da Comunicação.

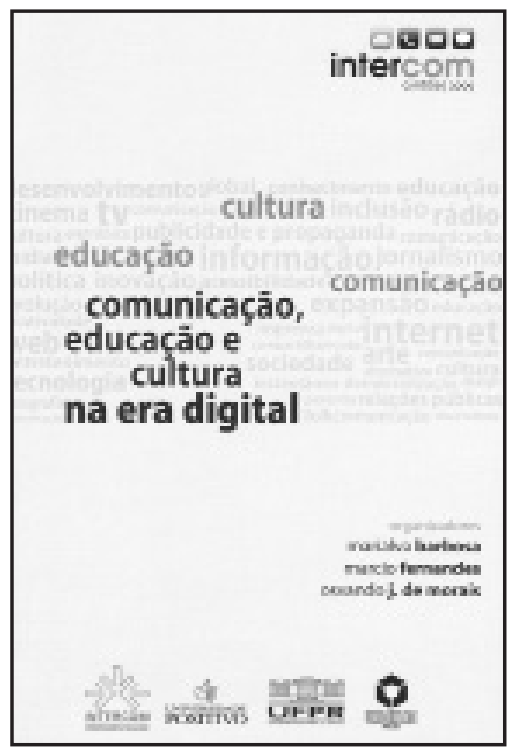

\section{FAÇA SEU PEDIDO}

pelo telefone (0xx11) 2574-8477,

e-mail: intercom@usp.br

ou acesse a Livraria Virtual da Intercom:

http://www.intercom.org.br 